\title{
Analytical and numerical investigation of fatigue crack growth in aluminum alloy
}

\begin{abstract}
The work presents a summary of previous studies on fatigue crack propagation within various Aluminum alloys. The effective characteristics on crack growth are first highlighted and the influence of surface engineering such as polishing, shot peening and skimming to enhance the failure resistance are discussed. Several different existing developed models for predicting the rate of crack propagation are compared in terms of incorporated effective parameters. Finally numerical and computational analyses as the accurate, fast and cheap methods which have attracted the Engineersôinterest are reviewed and compared with other methods.
\end{abstract}

Keyword: Al alloy; Computational analysis; Crack propagation; Numerical method; Surface engineering 